\title{
P 168 LET US SHOW THEM THAT THEY CAN! — INVOLVE THE YOUTH IN PALLIATIVE CARE PROVISION IN THE RURAL COMMUNITIES
}

Martha Njama. Prometra Kenya, Mombasa, Kenya

\subsection{6/bmjspcare-2014-000654.209}

Background The emerging cases for people who need palliative care is so overwhelming and it would not be right to leave the whole burden to the nurses only. It is important to involve other players; family members, community members, local leaders, church leaders and more importantly, the youth. Equipping the players with palliative care skills would drastically reduce the burden that is currently on the shoulders of the nurses.

Aims To educate and train the youth in the rural areas. To equip the youth with basic skills of palliative care provision aimed at enhancing palliative care provision within the communities and to show the youth that they have a big role to play in the community. To make the communities be less dependent on the nurses except for emergencies. Download some of the burden from the nurses. Increase community knowledge and understanding on how to handle patients with different terminal illnesses.

Results In Prometra Kenya youth program, 378 have been trained on various aspects of palliative care including 
communication skills. The youth have proved to be good learners and that they can effectively disseminate the information and pass the skills to their peers. They are being used by the communities as care providers.

Conclusions The youth are very energetic and they can be an important asset to the community if given the tools. They can be used to take care of the patients at home while the adults do other family activities. They appreciate the recognition by the communities. The adults are more productive as they use the time they would have used with the patients for other economic activities. The youth have a lot of untapped energy that can be helpful to the communities. The youth are cooperative, reliable and able to work closely with the adults and nurses. 